\title{
MOVILIZACIÓN Y RESISTENCIA VERDE: LOS CONFLICTOS SOCIOAMBIENTALES EN CHILE, 2000-2013
}

\author{
Camila Hernández \\ Pontificia Universidad Católica de Chile \\ chernandezs@uc.cl \\ Diego SAZo \\ Centro de Análisis e Investigación Política (CAIP), Chile \\ dsazo@uc.cl
}

\begin{abstract}
RESUMEN
Las masivas marchas ocurridas desde 2011 y el aumento en la paralización de proyectos de inversión, han dado cuenta de una sociedad civil más exigente y una autoridad más fiscalizadora frente a los impactos ambientales en Chile. Muchos se refieren al fenómeno, pero existe un déficit de estudios al respecto. Por lo tanto, el objetivo de este artículo es identificar, describir, analizar y jerarquizar los cien casos más significativos de conflictos socioambientales desde el año 2000. Los resultados se presentan a través de diez hallazgos relevantes, que entregan luces sobre el fenómeno de oposición a las iniciativas de inversión. Posteriormente, se establece un ranking histórico de intensidad de los conflictos, reconociendo patrones y tendencias que caracterizan este tipo de controversias.
\end{abstract}

Palabras clave: Conflicto socioambiental, Proyectos de inversión, Sociedad civil, Chile. 


\title{
MOBILIZATION AND GREEN RESISTENCE: THE SOCIO- ENVIRONMENTAL CONFLICTS IN CHILE, 2000-2013
}

\begin{abstract}
The massive protests occurred since 2011 and the increase in the suspension of investment projects, have reported a more demanding civil society and a more enforcing authority over environmental impacts in Chile. Many refer to the phenomenon, but there is a shortage of studies. Therefore, the aim of this article is to identify, describe, analyze and prioritize the hundred most significant cases of socio-environmental conflicts since 2000. The results are presented through ten relevant findings, which shed light on the phenomenon of opposition to investment initiatives. Subsequently, a historical ranking of intensity of the conflict is established, recognizing patterns and trends that characterize this type of disputes.
\end{abstract}

Keywords: Socio-environmental conflict, Investment projects, Civil society, Chile. 


\section{INTRODUCCIÓN}

El gobierno y los empresarios se encuentran en alerta ante las crecientes dificultades que enfrentan los proyectos de inversión en Chile. La inquietud es porque la oposición desde sectores de la sociedad civil se ha ampliado y profesionalizado, generando el retraso, rechazo e incluso la revocación de permisos ambientales. En esa línea, los conflictos de Barrancones (2010) ${ }^{1}$ e HidroAysén (2011) marcaron un antes y un después en la materia, al quedar en evidencia que las movilizaciones ciudadanas sí generaban efectos en las decisiones de la autoridad pública y los agentes inversionistas. Por lo tanto, no fue extraño que entre el 2012 y 2014, tras la activa resistencia de grupos organizados, se paralizaran proyectos de envergadura como Castilla $^{2}$, El Morro ${ }^{3}$, Pascua Lama ${ }^{4}$, Agrosuper-Freirina ${ }^{5}$ y el Parque Eólico Ancud $^{6}$, entre otros. Según el Servicio de Evaluación Ambiental (SEA), de los diez proyectos con mayor inversión comprometida en el país, siete se encontraban con algún tipo de traba institucional hasta el cierre de esta investigación. En cifras, el monto de inversión en incertidumbre ascendía a unos US\$ 20.000.000.000 aproximadamente (SOFOFA 2011).

Pese a su relevancia, el fenómeno de los conflictos socioambientales ha carecido de un estudio riguroso y sistemático que aborde integralmente el panorama de la oposición que enfrentan las iniciativas de inversión en Chile. ¿Cuáles son las controversias de mayor intensidad? ¿Cuáles son

1 Proyecto termoeléctrico emplazado cerca de la Reserva Nacional Punta de Choros (región de Coquimbo), que fue paralizado por decisión del presidente Sebastián Piñera (2010-2014) tras sucesivas protestas ciudadanas.

2 Proyecto termoeléctrico de la empresa brasileña MPX Energía, ubicado en la costa de la región de Atacama. El onto de inversión aproximado es de US\$ 4.400.000.000.

3 Iniciativa minera de la canadiense Goldcorp. Con una inversión aproximada de US\$ 2.514.000.000, se proyecta en la cordillera de la región de Atacama.

4 Proyecto minero de la transnacional Barrick Gold, emplazado en el sector cordillerano de Huasco (región de Atacama). Monto de inversión cercano a los US\$ 1.450.000.000..

5 Planta faenadora de cerdos de propiedad del grupo Vial. Con US\$ 500.000.000, se ubica en la comuna de Freirina (región de Atacama).

6 Iniciativa de tipo renovable no convencional de la empresa Ecopower. Posee un monto de inversión aproximado de US\$250.000.000. Se emplaza en la isla de Chiloé (región de Los Lagos). 
sus principales características? ¿Qué factores intervienen en su origen y desarrollo? ¿Qué impactos genera la oposición en los proyectos de inversión?

El objetivo de este artículo es identificar, describir, analizar y jerarquizar los casos más significativos de conflicto socioambiental en el país. Los resultados de la investigación se presentan a través diez hallazgos relevantes referidos a las características generales, los rasgos particulares y las variables que influyen en el desarrollo de estas controversias. Posteriormente, mediante la formulación de una metodología propia, establecemos un ranking histórico de intensidad de los conflictos, a partir de una ponderación de variables intervinientes como indicadores proxy del grado de fuerza con que se expresa la resistencia. Finalmente, identificamos patrones y tendencias de los conflictos según su nivel de intensidad.

\section{EL CONFLICTO Y SU VARIANTE SOCIOAMBIENTAL}

La noción de conflicto varía según el enfoque de aproximación. Ante todo, un conflicto será social cuando trasciende la esfera de lo individual y procede desde la propia estructura de la sociedad (Coser 1965). Una definición clásica de conflicto social lo entiende como "un proceso de interacción contenciosa entre actores sociales e instituciones, movilizados con diversos grados de organización y que actúan de manera colectiva de acuerdo con expectativas de mejora, de defensa de la situación preexistente o proponiendo un contraproyecto social" (Lorenzo 2001: 12).

El objeto del conflicto social es "generar la restauración de un derecho (positivo, natural o subjetivo) que se estima quebrantado o bien la creación de una norma que pretende remediar una situación que se estima injusta" (Oro 2013: 74). Así, para que ocurra un conflicto social los actores deben adquirir la "convicción de que son negados ciertos derechos que les corresponden" (Coser 1965: 40). En ocasiones extremas, la voluntad de romper la "resistencia del otro abre la opción del recurso de la violencia, que puede, llegado el caso, tender al aniquilamiento físico del otro" (Freund 1995: 58).

Una de las formas de expresión del conflicto social es la protesta, entendida como la "instancia de contestación en la que los cuerpos, símbolos, identidades, prácticas y discursos son usados para perseguir o impedir cambios en las relaciones de poder institucionalidades" (Van Dyke 2003: 268). Según Sydney Tarrow, el proceso de modernización de las sociedades posee un contenido dialéctico de apertura y resistencia que estimula la movilización de las personas (Tarrow 2009: 44). Afirma que existen ciclos de protesta donde la gente participa en acciones colectivas como respuesta a un cambio en la pauta de las oportunidades y restricciones 
políticas (Tilly 2010). Alternativamente, Klandermans distingue tres tipos de ciclo protestatario: el estacional, relacionado a periodos recurrentes de actividad; el institucional, que se relaciona con las funciones de cada actor colectivo; y el de acción y movilización, conectado directamente con la estrategia de las organizaciones e impulsado por estas según su cálculo específico de oportunidades González Calleja 2013: 15). Respecto a la ocurrencia, Dalton ha demostrado que la cantidad de protestas aumenta significativamente en las sociedades industriales avanzadas, principalmente porque el alto desarrollo político y económico proporciona los recursos adecuados para aquellos que tienen demandas políticas (Dalton, Van Sickle y Weldon 2010). También porque la democratización estimula la formación de movimientos sociales, los que como modalidad de contienda política fomentan los actos de contestación (Della Porta y Diani 1999).

En este marco conceptual, un conflicto socioambiental se entenderá como aquel "proceso de interacción entre actores privados o públicos, individuales o grupales, caracterizado por una dinámica de oposición y controversia fundada en la incompatibilidad o en la percepción de incompatibilidad en torno a; 1) el uso, acceso y/o preservación del ambiente y sus recursos; y 2) las condiciones de calidad de vida de las comunidades" (Reyes et al. 2011). Como indican varios autores, es conveniente señalar que la noción de conflicto ambiental es limitada, pues los aspectos involucrados poseen un mayor alcance, siendo el medioambiente solo uno de los elementos que genera desacuerdo, ya que también tienen protagonismo otros factores como los sociales, económicos, culturales y políticos. De ahí que sea más apropiado utilizar el adjetivo socioambiental.

\section{EL CASO CHILENO}

Producto de la magnitud y frecuencia de las protestas callejeras, el año 2011 ha sido considerado como el de mayor activismo social en las dos últimas décadas en Chile (Segovia y Gamboa 2012). Si bien las causas de las reclamaciones fueron múltiples, en general respondieron a expresiones de contestación hacia la autoridad para obtener, defender o cuestionar determinados intereses. El agitado 2011 comenzó con turbulencias en la zona extrema de Magallanes, continuó con la multiregional resistencia al proyecto HidroAysén y concluyó con la arremetida nacional de los estudiantes contra el sistema educativo. Para muchos, esta masiva apropiación del espacio público como escenario de reclamación alteró las prácticas de una ciudadanía que, tras el retorno de la democracia, había optado por volcarse a la esfera privada y mantenerse ajena de las demandas de orden colectivo (Moulian 1997). Siguiendo la lógica de Dalton, el alto desarrollo político y económico de Chile proporcionó las condiciones 
adecuadas para estimular a aquellos que tenían demandas políticas (Dalton, Van Sickle y Weldon 2010). Para el caso chileno del 2011, lo llamativo fue que las expresiones de descontento fueron multisectoriales, pues además de exigencias de reformas al modelo educacional, también hubo demandas por regionalismo, derechos civiles y preservación del medioambiente. La extensión del fenómeno social incluso generó la atención de medios internacionales, que catalogaron al suceso como el invierno chileno ( $E l$ País 21/08/2011), asimilando el proceso a manifestaciones de descontento global (The New York Times 04/08/2011, The Economist 27/08/2011).

En cuanto a las causas, diversas han sido las interpretaciones sobre lo acontecido en nuestro país. Mientras algunos atribuyen las protestas a un evidente signo de desmoronamiento del modelo económico (Mayol 2012), otros lo consideraron como un empoderamiento de los ciudadanos en búsqueda de una democracia más activa y deliberativa (Salazar 2012). También existen lecturas que pusieron el acento en una rebelión contra el poder, focalizada en su forma de distribución y uso, cuya expresión más visible apuntaría a la "cada vez más escasa legitimidad del sistema político" (Navarrete 2011). Por último, existen análisis que relativizaron este malestar y lo atribuyeron a una condición histórica de los países en desarrollo (Oppliger y Guzmán 2012) o bien a una "exigencia ciudadana por más modelo y ajustes a lo que ya existe” (Larraín 2011).

Con todo, la generalidad de los diagnósticos coincidió en que Chile se encuentra en un proceso de transformación, siendo una de sus dimensiones más visibles la nueva dinámica de relación entre las grandes empresas y la sociedad, que se ha vuelto cada vez más compleja. ¿En qué se manifiestan estos cambios? A nivel político, en la presencia de una autoridad que promueve un discurso más crítico y fiscalizador en contra de las empresas, sancionando fuertemente la ocurrencia de situaciones irregulares. Casos representativos son los dictámenes en contra de compañías farmacéuticas (Emol 31/01/2012), del retail (La Tercera 25/04/2013), industria alimentaria (La Segunda 25/05/2012) y del sector energético (La Tercera 30/08/2012). En segundo lugar, en la emergencia de una ciudadanía más activa, exigente y organizada, mayormente dispuesta a expresar su malestar y desconfianza hacia las empresas. Según encuestas de opinión pública, mientras en América Latina el promedio de confianza hacia estas compañías es de un 38\%, en Chile solo alcanza un 16\% (Latinobarómetro 2011, UDP 2011). Tercero, culturalmente, la sociedad chilena ha tendido a incorporar nuevos principios en su escala de valores, en sintonía con los procesos de modernización reflexiva (Beck, Giddens y Lash 2008), que otorgan mayor relevancia a la transparencia, la tolerancia, la equidad y la preservación del medioambiente. Por último, el cambio también se expresa 
en los medios de comunicación, que han asumido un rol más activo en la denuncia de los procesos empresariales, otorgando mayor tribuna a los reclamos ciudadanos. Si antes el principio directriz en la entrega de información era la objetividad ante las audiencias, hoy tiende a ser la transparencia (Rosen 2001). El rol de CIPER Chile en los últimos años resulta revelador (Skoknic 2013).

Es precisamente en este escenario donde la presente investigación se focaliza en indagar una de las dimensiones de estos signos de cambio social, con relevancia y proyección creciente: los conflictos socioambientales.

\section{METODOLOGÍA}

Esta investigación es de naturaleza exploratoria, descriptiva e inferencial. No plantea una hipótesis porque su objetivo no es otro sino esclarecer los contornos de un problema sin evidencia sistematizada ${ }^{7}$. Por ello, ante la carencia de un catastro oficial, la selección de la muestra fue intencionada y se formuló a partir de los casos con mayor repercusión mediática en la última década según fuentes de información pública8. Se partió del siguiente supuesto metodológico: a mayor fuerza de los grupos opositores, mayor la exposición mediática del conflicto. De un total de 124 conflictos identificados entre enero de 2000 y abril de 2013, se seleccionaron los 100 que tuvieran más frecuencia de exposición pública y que contaran con algún indicio de conflictividad en los últimos cinco años?

Cada controversia se vinculó al nombre del proyecto de inversión involucrado ${ }^{10}$. Los criterios de caso fueron cuatro. Aquellos proyectos que:

7 Solo se han registrado aproximaciones orientadas a mapear algunos de estos conflictos, pero sin hacer uso de metodologías y herramientas estadísticas que suministren información adecuada. Un buen ejemplo es el Mapa de Conflictos Socioambientales en Chile del Instituto Nacional de Derechos Humanos (2012).

8 Documentación de plataformas del Estado (requerimientos ante el SEA, Comité de Ministros o solicitudes vía Ley de Transparencia), publicaciones académicas y reportes de medios de comunicación.

9 Si bien los conflictos socioambientales cuentan con ciclos irregulares de intensidad en el tiempo, se ha podido constatar que las expresiones de hostilidad se manifiestan con una periodicidad de al menos dos o tres años.

10 Por proyecto se entiende todo emprendimiento vinculado a una actividad industrial, indistintamente de si se encuentra en su etapa de evaluación, operación, o cierre. 
1. Por sí mismos han generado la emergencia de oposición organizada.

2. Siendo de titulares diferentes, provocan la misma oposición y resistencia.

3. Siendo del mismo titular, se encuentran cercanos en el mismo espacio territorial.

4. Siendo del mismo titular, se encuentran ubicados en distintos sectores de un mismo espacio provincial.

El análisis descriptivo e inferencial se formuló según los resultados de una base de datos construida a partir de la identificación de treinta variables para cada caso. Se agruparon en cuatro grandes dimensiones. A continuación se presentan las más relevantes ${ }^{11}$.

\section{Tabla 1: Variables intervninientes en un conflicto socioambiental}

Industria Ubicación Oposición Cobertura comunicacional

\begin{tabular}{|c|c|c|c|}
\hline Rubro & Región & Tipo de oposición & Medios nacionales \\
\hline $\begin{array}{l}\text { Resolución } \\
\text { ambiental }\end{array}$ & Provincia & Nivel organizativo & $\begin{array}{c}\text { Medios } \\
\text { internacionales }\end{array}$ \\
\hline $\begin{array}{c}\text { Tipo de evaluación } \\
\text { ambiental }\end{array}$ & $\begin{array}{c}\text { Comuna } \\
\text { Zona } \\
\text { (rural/urbana) }\end{array}$ & $\begin{array}{c}\text { Involucramiento de } \\
\text { Gubernamentales } \\
\text { (ONG) }\end{array}$ & Redes sociales \\
\hline $\begin{array}{l}\text { Conflictos por el } \\
\text { agua }\end{array}$ & & $\begin{array}{c}\text { Apoyo } \\
\text { internacional }\end{array}$ & \\
\hline & & $\begin{array}{c}\text { Judicialización } \\
\text { nacional }\end{array}$ & \\
\hline & & $\begin{array}{l}\text { Judicialización } \\
\text { internacional }\end{array}$ & \\
\hline & & Actos violentos & \\
\hline & & Años del conflicto & \\
\hline
\end{tabular}

Fuente: Elaboración propia.

11 Para mayor detalle de la operacionalización de las variables, contactar a los autores vía correo electrónico. 


\section{PRINCIPALES HALLAZGOS}

De los CIEN CONFlictos MÁs RELEVANTES, MÁs de LA MiTAD SE ENCUENTRA ACTIVO EN ACCIONES DE OPOSICIÓN

La centena de casos seleccionados confirma la amplitud del problema ambiental y demuestra la mayor disposición desde la sociedad civil a presentar resistencia a las iniciativas. Según la muestra de casos, el 74\% de los proyectos involucrados en un conflicto se encuentra aprobado por la autoridad ambiental, mientras que el resto está en fase de evaluación (11\%) o bien rechazado, revocado, suspendido, desistido o no calificado (12\%). Un 3\% ni siquiera ha sido ingresado al sistema. Lo anterior revela que independiente del respaldo institucional, la resistencia a los proyectos se puede generar en cualquiera de las etapas (exploración, evaluación, construcción, operación o cierre).

La situación de conflictividad se puede distinguir bajo tres criterios: según su vigencia actual, la permanencia en el tiempo y la actividad desde la oposición. En ese marco, la mayoría de los cien casos se encuentra en condición de activos (53\%). Los conflictos consolidados ${ }^{12}$ corresponden al $18 \%$, mientras que los que declinan ${ }^{13}$ figuran con el $12 \%$. Aquellos que se vislumbran al alza ${ }^{14}$ concentran el $8 \%$, los incipientes ${ }^{15} 6 \%$, y finalmente los concluidos ${ }^{16}$ solo un $3 \%$ de la muestra.

12 Es decir, el conflicto es vigente, posee una permanencia en el tiempo y en las actividades de oposición.

13 Controversias que presentan al menos dos años de inactividad en la resistencia.

14 Conflictos con aumento sostenido en la intensidad de oposición.

15 O sea, con al menos dos años desde que se registra su origen.

16 Independiente de sus motivos, el conflicto no está vigente. 


\section{Gráfico 1: Estado actual de los conflictos. Porcentajes}

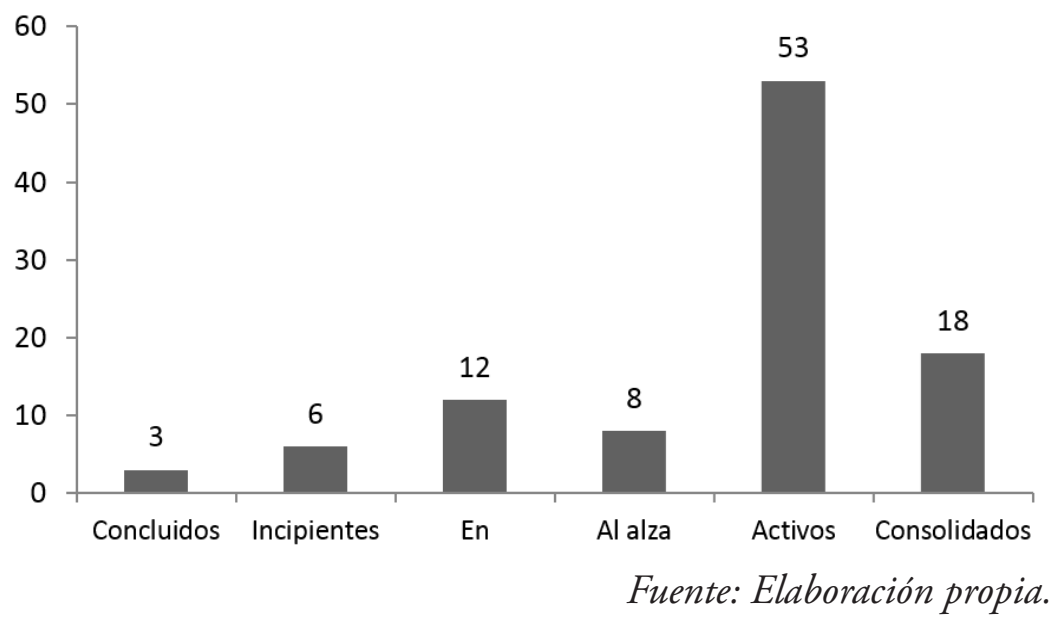

LOS CONFLICTOS SE DEFINEN POR EL TIPO DE IMPACTO QUE PRODUCEN LAS INDUSTRIAS. EN TOTAL SE IDENTIFICAN OCHO RUBROS QUE CONCITAN OPOSICIÓN

En Chile, los conflictos socioambientales se distribuyen en ocho grandes industrias: minería, termoeléctrica, hidroeléctrica, forestal, salmonicultura, agroindustria, construcción y otras industrias ${ }^{17}$, que se diferencian por el impacto que generan y por la oposición que enfrentan.

Son tres los rubros de mayor conflictividad: en primer lugar la minería, que concentra un $28 \%$ del total de los casos; luego el sector termoeléctrico con $22 \%$ y seguidamente la hidroelectricidad, con $21 \%$. Es importante considerar que la sumatoria de dichas industrias asciende al $71 \%$ de los casos de conflictividad en el país. Por otro lado, destacan las empresas de residuos, rellenos sanitarios y ERNC con 10\%; luego el sector forestal con $8 \%$. Con menor presencia está el sector de la construcción con 5\%, la agroindustria con $4 \%$ y finalmente el sector salmonicultor representando el $2 \%$ de las controversias.

17 Se incluyen proyectos de Energías Renovables No Convencionales (ERNC), plantas de combustibles, relleno sanitario, aguas servidas, incineración, entre otros. 


\section{Gráfico 2: Distribución de conflicto por rubro. Porcentajes}

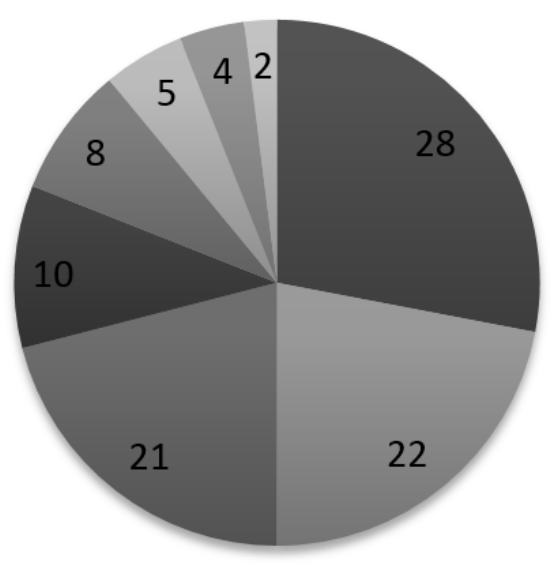

- Minería

- Termoeléctricas

- Hidroeléctricas

- Otros

Forestal

Construcción

Agroindustria

Salmonicultura

Fuente: Elaboración propia.

La elevada cifra de la minería tiene directa relación con la cantidad de iniciativas desarrolladas en la zona norte del país, espacio geográfico donde se ubican las mayores riquezas de este tipo, siendo Coquimbo (32\%) la región con mayores controversias de este tipo. Las causas se relacionan principalmente con la contaminación del agua y el agotamiento de las cuencas. Otros catalizadores se asocian a externalidades negativas como la población minera flotante, tornaduras, polvos en suspensión y la presencia de relaves tóxicos en las cercanías de asentamientos humanos ${ }^{18}$.

El rubro termoeléctrico se distribuye geográficamente en nueve regiones, siendo la región de Valparaíso la que presenta el mayor número de controversias. La oposición a este rubro se funda en el impacto que genera producto de las emisiones de material particulado ${ }^{19}$. Al ecosistema, los perjuicios se relacionan con los cambios provocados en la temperatura del agua de mar, que altera el modo de vida de las especies marinas.

18 Una reciente investigación constató la existencia de 449 tranques y embalses tóxicos: 324 inactivos y 125 activos a lo largo del país (Cámara de Diputados 2011: 2-16).

19 Según la IVEncuesta de Percepción y Actitudes hacia el Medio Ambiente (2013) del Centro de Investigación para la Sustentabilidad y Estudios Cuantitativos de la Universidad Andrés Bello, el 50\% de los encuestados piensa que la energía termoeléctrica a carbón es la más contaminante, seguida por la termoeléctrica a petróleo con un $28 \%$, y la energía nuclear con un $13 \%$. 
En cuanto a los proyectos hidroeléctricos, la región del Bío Bío y la de Los Ríos poseen el mayor número de controversias, ambas con $24 \%$. Principalmente porque dada sus condiciones hidrográficas cuentan con mayor número de represas construidas. La oposición reclama la inundación de tierras cultivables, efecto negativo en la biodiversidad, disminución y cambios en el caudal de los ríos y el desplazamiento de personas (The World Commission on Dams 2000: 19-20). Dentro de los grupos que componen la oposición se destacan los de tipo indígena, que reclaman por la afectación de ríos y zonas que consideran sagradas. Lo anterior se ha potenciado por la incorporación a la legislación nacional del Convenio 169 de la Organización Internacional del Trabajo (OIT), que provee un marco jurídico favorable para los pueblos originarios pues cautela su participación y sus derechos en la toma de decisión que los involucran (Montt y Matta 2011: 133-212). Junto a ellos se destacan actores gremiales, como agricultores y grupos asociados al turismo, que se ven afectados por la escasez o cambios que pueden producir las centrales en el nivel de las cuencas.

La industria forestal por su parte tiene dos fuentes principales de conflicto: las plantas de celulosa y el manejo de bosques. Se distribuye principalmente en la zona sur del país, siendo el Maule la región con mayor presencia de polémicas $(38 \%)$. La oposición se configura a través de agentes políticos y locales, aunque también se observa la importancia de los grupos indígenas, que utilizan la violencia recurrentemente (63\%), destacándose por sobre el resto de los rubros (41\%).

En la industria de la construcción se destacan proyectos como embalses, inmobiliarias y obras públicas de envergadura. En términos generales no se ha constituido un foco conflictivo en torno a esta industria, debido a la amplia gama de proyectos que difieren en sus impactos a la población. Esta condición heterogénea dificulta la emergencia de una oposición altamente organizada y que pueda servir de modelo en otros frentes.

Por su parte, el impacto generado por la agroindustria se manifiesta por la contaminación odorífera y de las aguas residuales. La organización de la oposición se encuentra aún en fase inicial, por lo que la resistencia aún no posee altos niveles de profesionalización. Existe un alto porcentaje de utilización de la violencia, lo que responde a que los impactos son muchos más directos para las comunidades que se encuentran en el entorno; sin embargo no existen patrones que reflejen el uso de estrategias premeditadas.

Para el sector salmonicultor, se consideraron solo dos conflictos (Marine Harvest y Mainstream Chile), al ser los más representativos del rubro. Ambos se encuentran en la región de Los Lagos, y son motivados 
principalmente por impactos asociados a la producción, como la descarga de materia orgánica y la acumulación de desperdicios y desechos, entre otros (Fundación Terram 2001). El modelo de oposición es uno de los más completos respecto de las variables analizadas, pues la resistencia se encuentra altamente institucionalizada, existe un alto involucramiento de las ONG y cuentan con un gran apoyo internacional a diferencia de la mayoría de los conflictos (SIAE Consultores 2011).

Finalmente, en la categoría otros (The New York Times 04/08/2011, The Economist 27/08/2011, las características de oposición se relacionan con las particularidades de cada caso. En su mayoría presentan bajos niveles de organización, con poca participación de agrupaciones ambientalistas y uso de estrategias violentas. Sin embargo, se destacan los casos de Biogesur y Pellets CMP, los que serían los más visibles de la categoría debido a su extensión en el tiempo.

\section{A NIVEL GEOGRÁFICO, LA MAYOR CONCENTRACIÓN DE CONFLICTOS SE REGISTRA EN LA ZONA NORTE DEL PAÍS}

La distribución geográfica de estas controversias está definida por una irregular curva desde el norte hacia el sur. En efecto, el Norte Grande concentra el $15 \%$ de los conflictos, mientras que el Norte Chico el 22\%. La zona centro registra el 30\%, al igual que la zona sur. Por último, la zona austral registra solo el 3\%. La concentración en el norte se explica porque este territorio históricamente ha sido considerado con un espacio de desarrollo para grandes proyectos extractivos, en particular por las riquezas naturales que alberga. Las regiones de Atacama y Coquimbo son las de mayor frecuencia ( $11 \%$ cada una). Diferente es el caso del extremo sur, donde las dificultades geográficas han limitado la exploración masiva de iniciativas.

Las provincias de Elqui y Huasco albergan el mayor número de conflictos al presentar siete casos. Les siguen Valparaíso con seis y luego Valdivia con cinco. Estas cuatro provincias aglutinan el 25\% de los conflictos socioambientales del país y presentan proyectos emblemáticos como Pascua Lama, CODELCO Ventanas y CELCO Valdivia.

En el nivel comunal, los cien casos se distribuyen en 71 unidades a los largo del territorio. El universo de comunas en Chile es 346, por lo que los conflictos se concentran solo en un $21 \%$ de ellas, siendo los sectores rurales los más afectados (61\%). Las comunas de Putre y Panguipulli son las que más concentran, con cuatro casos cada una. Luego se encuentran Huasco, Andacollo y Calama con tres casos. 


\section{Gráfico 3: Distribución geográfica de los conflictos socioambientales}

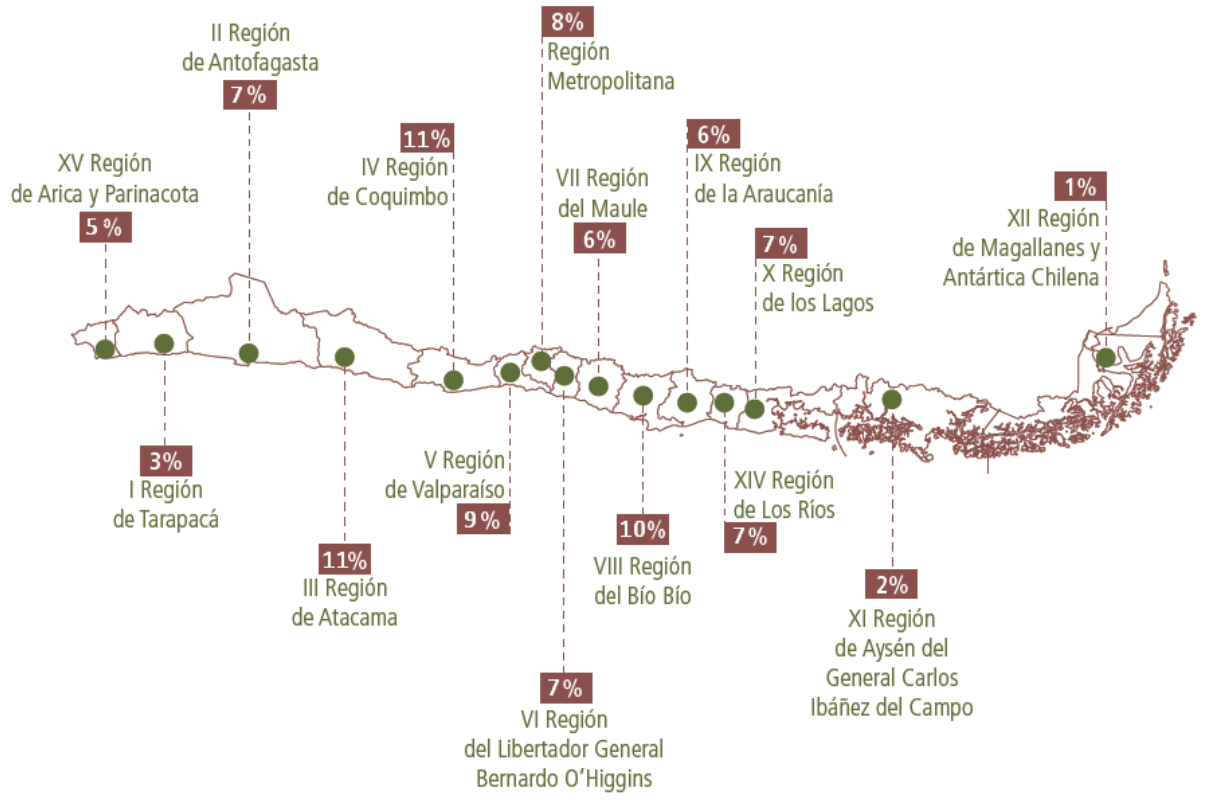

Fuente: Elaboración propia.

\section{EN LA ÚlTiMA DÉCADA, SE REGISTRA UNA TENDENCIA AL ALZA EN LA OPOSICIÓN A INICIATIVAS DE INVERSIÓN}

Si bien el origen de estas controversias radica en múltiples causas, la preocupación por el medioambiente ha sido una de las más relevantes. Encuestas de opinión pública muestran que conforme avanzan los años la ciudadanía otorga mayor importancia a este tipo de temas, con un $62 \%$ (Auditoría a la Democracia 2012), en particular las generaciones más jóvenes (UDP-Feedback 2012). Frente a esta nueva realidad, tanto el Poder Ejecutivo como el Legislativo han tenido que responder proponiendo, desarrollando y sancionando una legislación más acorde con los intereses ciudadanos. Así se explica la creación de instituciones como el Ministerio del Medio Ambiente (2010), los Tribunales Ambientales (2012) y la Superintendencia de Medio Ambiente (2013).

A pesar de la respuesta institucional, este nuevo escenario acumula mayores muestras efectivas de oposición. Las cifras indican que el 55\% de las controversias más relevantes encuentra su origen en los últimos seis años, lo que marca un fuerte cambio respecto a épocas pasadas, donde la instalación de proyectos suponía la aceptación generalizada de 
las comunidades afectadas. Incluso, la magnitud de la iniciativa tendía a ser proporcional al grado de acogida (El Mercurio 15/05/2011). Ahora el umbral de exigencias de la ciudadanía ha aumentado y ante cualquier afectación de intereses existen las condiciones e incentivos necesarios para hacer patente el malestar.

\section{Gráfico 4: Origen temporal de los conflictos. Porcentajes}

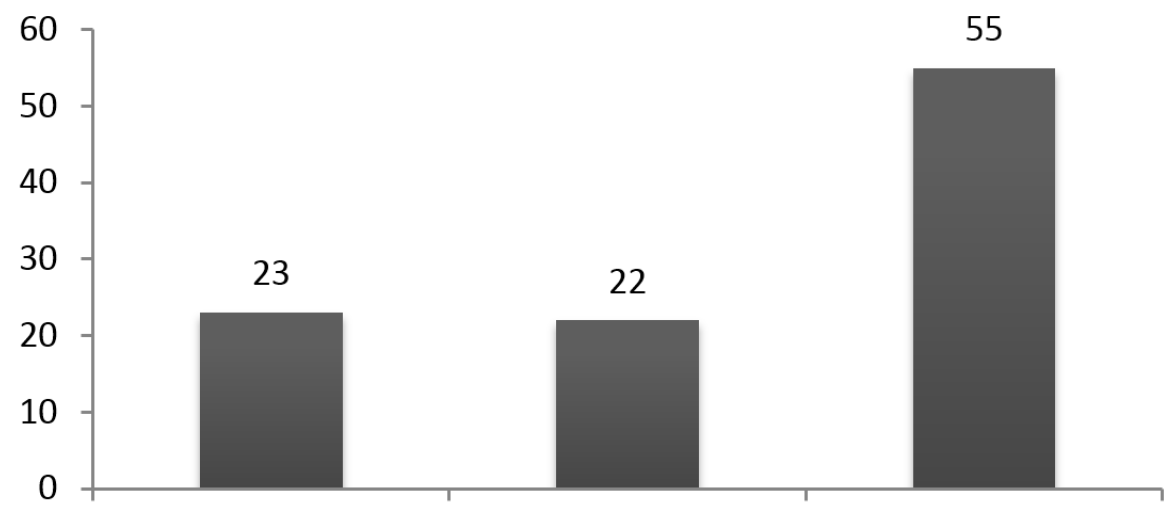

Previo 2000

De 2000 a 2007

De 2008 a 2013

Fuente: Elaboración propia.

EN GENERAL, EL ORIGEN DE LAS CONTROVERSIAS SE ASOCIA A CONFLICTOS POR EL AGUA E INTERVENCIÓN DE ZONAS PROTEGIDAS POR EL ESTADO

Las causas y características de estos conflictos son complejas y se encuentran sumamente relacionadas. Además del impacto ambiental, cambios en la calidad de vida de la población, ubicación del proyecto y escasez de ciertos recursos, también se observan problemas administrativos, relacionados con eventuales irregularidades de procedimiento en el sistema de evaluación ambiental y de falta de transparencia.

En este escenario es posible afirmar que el agua es uno de los factores relevantes en el origen de estos conflictos (Chilesustentable 2010: 15-54), pues el 56\% de ellos involucra al vital elemento, sea por uso, acceso o contaminación. La lucha por el recurso está íntimamente relacionada con los proyectos debido a la envergadura que suponen. La necesidad de las industrias por adquirir agua, o los impactos que generan en las fuentes de abastecimiento potable, ha provocado intensas controversias con las comunidades. Aunque los conflictos por el agua son un fenómeno transversal a los rubros, existe una estrecha relación entre este factor y la industria de la minería, pues en el $86 \%$ de estos casos se identifica al agua como una de las causas de los conflictos. 
En cuanto a la localización espacial de los conflictos por el agua, se presentan diferencias en la distribución por región. En ciertas zonas el agua supone un recurso más valorado debido a su escasez, por lo que las comunidades le otorgan un mayor valor $y$, en consecuencia, un mayor rechazo a aquellas actividades que lo afectan. Las regiones que presentan mayores casos son Arica y Parinacota (100\%), Maule (83\%), Coquimbo (73\%), Araucanía (67\%), Atacama (64\%) y Los Lagos (57\%). Los casos del norte y centro del país se relacionan principalmente con el fenómeno de la escasez hídrica, mientras que la Araucanía y Los Lagos con el impacto que suponen las centrales hidroeléctricas.

Por otro lado, la intervención de zonas protegidas por el Estado también se ha identificado como factor recurrente dentro de las causas de los conflictos socioambientales. Aunque la cifra no es particularmente alta $(18 \%)$, se deben tomar en cuenta aquellos casos donde la condición del territorio se encuentra en controversia $(18 \%)^{20}$. La minería es la industria con mayor presencia, alcanzando un $29 \%$ de los casos. Sin embargo, es importante destacar que aunque las hidroeléctricas representan solo el $17 \%$, los casos en controversia llegan a un $44 \%$. Esto se debe a que al encontrarse en la zona sur del país, muchas veces estos proyectos impactan sectores de parques nacionales o bien territorios considerados sagrados por los indígenas, no estando determinado si se encuentran protegidos o no por la Corporación Nacional de Desarrollo Indígena (CONADI).

\section{EXISTEN SIETE TIPOS DE GRUPOS QUE MANIFIESTAN OPOSICIÓN A LOS PROYECTOS Y SE DISTINGUEN PRINCIPALMENTE POR SUS RASGOS Y MOTIVACIONES EN PARTICULAR}

En la resistencia a los proyectos se encuentran actores individuales, colectivos, locales y nacionales, que difieren en características, contenidos y razones por las cuales se oponen. Lo anterior impide agruparlos en un solo actor y exige el intento por dilucidar las diferencias entre sí. En este estudio se han identificado siete grupos:

20 Es decir, no existe total claridad respecto a si corresponde legalmente o no a una zona de protección. 


\section{Gráfico 5: Tipo de oposición en conflictos. Porcentajes}

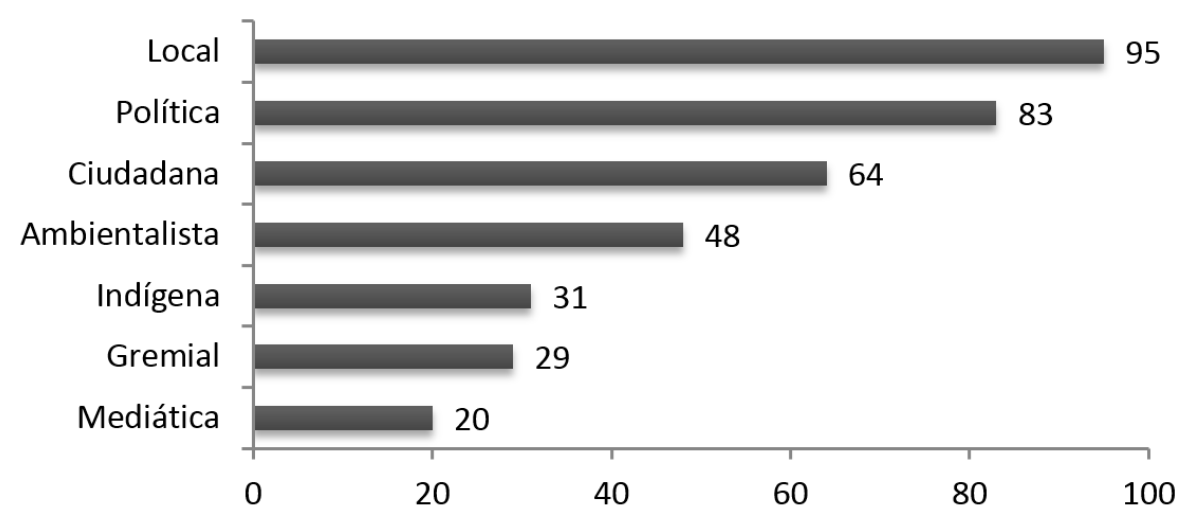

Fuente: Elaboración propia.

En primer lugar, la oposición local, referida a las personas y comunidades que viven en el lugar de emplazamiento de los proyectos, se registra en la gran mayoría de los casos (95\%), debido a que son los que se ven afectados directamente por los impactos.

El segundo tipo es la oposición política, asociada a las autoridades en las esferas legislativa y comunal. El nivel de presencia es alto (83\%), pues existen incentivos electorales para involucrarse: un agente político que adhiere a reclamaciones locales logra legitimar y consolidar sus bases en vistas a futuros procesos eleccionarios.

Luego registramos la de orden ciudadana, caracterizada por individuos organizados que se movilizan por la causa no siendo parte de la comunidad afectada. En general esta oposición se vincula a sectores juveniles de la población, sensible a la preservación del medioambiente y con acceso a plataformas digitales, que les permite formular resistencia independiente de la lejanía con los lugares afectados. El 64\% de los conflictos cuenta con este tipo de activismo.

La oposición ambientalista, referida a las ONG oficialmente constituidas en el país, cuenta con un limitado nivel de involucramiento (48\%). Esto se explica por la estrechez de sus cuadros y recursos, que dificulta la participación activa en todos los conflictos que se registran (SIAE Consultores 2011). Frente a ese panorama, estos grupos han optado por privilegiar los casos más significativos, donde la magnitud de la inversión, impacto ambiental y cobertura desde los medios son los criterios determinantes.

La resistencia indígena, relacionada a los individuos y grupos que poseen oficialmente la condición de pueblo originario, tiene presencia en el 31\% 
de los casos. En general, no expresan adherencia hacia otros conflictos, lejanos y ajenos a la naturaleza de sus demandas, por lo que se concentran en sus propios ámbitos de interés. Esto explica que la cifra en la generalidad de la muestra sea limitada.

La oposición gremial, que incluye las organizaciones sectoriales de la sociedad civil, está presente en el $29 \%$ y se produce principalmente por el acceso o restricción de los recursos naturales disponibles, y que son demandados por estos actores y los titulares de los proyectos. En esta tipología se destacan los gremios de pescadores, agricultores, turismo, entre varios otros.

Finalmente la oposición mediática, que agrupa a distintos referentes de la opinión pública que contribuyen al posicionamiento de la resistencia, registra un $20 \%$ de presencia. Si bien esta dimensión es la más baja de todas, evidencia una tendencia al alza luego de casos exitosos que explotaron esta alternativa (caso Barrancones) ${ }^{21}$.

\section{LOS GRUPOS DE OPOSICIÓN POSEEN UNA ORGANIZACIÓN DE MEDIANA SOFISTICACIÓN Y TIENDEN A EJECUTAR ACCIONES REACTIVAS Y SIN UNA PLANIFICACIÓN ESTRATÉGICA EN EL TIEMPO}

Siguiendo propuestas metodológicas sobre modelos de oposición, los grupos se pueden distinguir en tres niveles a partir del grado de organización interna ${ }^{22}$. En el caso chileno, el nivel promedio es medio y se caracteriza por la intermitencia en los actos de resistencia y por la ausencia de lineamientos de largo plazo, lo que se asocia comúnmente a los conflictos de mayor amplitud en nuestro país, es decir, condición de activo (50\%). Los grupos más organizados, que despliegan con mayor frecuencia y magnitud la resistencia, se relacionan con los conflictos de orden consolidado (56\%). En consecuencia, queda en evidencia que a mayor nivel de articulación,

21 La cancelación de este proyecto tuvo, entre sus motivos, la activa participación de celebridades de la televisión, que a través de mensajes virales por internet incentivaron a la opinión pública a oponerse a la iniciativa. Asimismo, hicieron reiterados llamados a la autoridad para revertir su autorización, lo que al final generó resultados.

22 La articulación del consenso hostil tiene tres etapas de desarrollo: la primera, la fase de formación, corresponde al momento donde los grupos reconocen la existencia de un conflicto y expresan incipientemente la voluntad de manifestar resistencia. El segundo, llamado movilización, consiste en un estado superior donde organización donde, a pesar de contar con acceso limitado a recursos, se generan acciones permanentes de oposición en el tiempo. La última fase, la institucionalización, se refiere al más alto nivel de capacidad organizativa, donde existe profesionalización de los cuadros y una alta disponibilidad de recursos (Lorenzo 2001: 132-133). 
mayores son las opciones de que la controversia adquiera una condición de hostilidad significativa.

En cuanto a las estrategias de oposición, la alternativa judicial ha evidenciado un sostenido aumento en los últimos ańos, duplicándose desde el 2008. Según cifras del SEA, previo a ese año, el promedio de juicios ambientales se reducía a nueve por año, mientras que en el rango que comprende el 2009 y 2011 aumentó a un promedio anual de diecisiete recursos $^{23}$. De los cien conflictos más significativos, al menos el $72 \%$ se encuentra con indicios de judicialización ${ }^{24}$. La validez del instrumento se puede explicar por su efectividad y por la representación de un cuestionamiento a la institucionalidad ambiental, que para los intereses de la ciudadanía adolece de poder decisional en el proceso de aprobación de proyectos $^{25}$.

Respecto del Convenio 169 de la OIT, al menos un 29\% de los casos cuenta con reclamaciones de este tipo, aunque no todas ellas son transferidas a instancias judiciales ${ }^{26}$. Como señalan cifras del SEA, desde la puesta en marcha de la normativa en 2009, se han registrado diecisiete recursos judiciales por este tipo, siendo efectivos en cinco casos. Tres de los cinco paralizados por la Corte Suprema tienen como fundamento la vulneración del derecho a consulta de los pueblos indígenas (Parque Eólico Ancud, Paguanta y El Morro). Los casos tienden a asociarse con conflictos hidroeléctricos y mineros, ubicados en zonas con presencia de población indígena reconocidas por la CONADI.

23 Con todo, según la Ministra del Medio Ambiente, María Ignacia Benítez, no se puede hablar de una excesiva judicialización en tanto "de 1.200 proyectos que aproximadamente se califican al ańo, solo se presentan 20 recursos de protección en promedio" (Pulso 21/08/2012).

24 Diferente es la dimensión internacional, donde solo dos casos han sido admitidos en la Comisión Interamericana de Derechos Humanos: Pascua Lama y ENDESA Alto Bío Bío.

25 Según Auditoría a la Democracia (2012) un 62\% de los chilenos considera que sus demandas ante proyectos ambientales no serían consideradas por las autoridades.

26 El bajo número se debe entender en el marco de su reciente vigencia en el sistema institucional chileno. Si se considera que la normativa se encuentra en vigor desde el 2009, su importancia relativa aumenta, pues en solo tres años ha logrado estar presente en más de un cuarto de los conflictos del país. 
Por el lado de las acciones de violencia, pese a que en los últimos años existe una tendencia a tolerarla como expresión de malestar (Mayol y Azócar 2011), aún no se validan como instrumento de presión, pues solo un $41 \%$ de los conflictos registra eventos relevantes de este tipo. Su uso es motivado por situaciones de corto plazo, asociados a la necesidad de llamar la atención de autoridades, titulares y medios de comunicación, frente a eventos considerados como una agresión para la comunidad y de la que se espera una rápida solución.

EL INVOLUCRAMiENTO DE LAS ONG AMBIENTALISTAS ES BAJO Y SE FOCALIZA EN LOS CONFLICTOS DE MAYOR IMPACTO Y VISIBILIDAD PÚBLICA

Según estudios al respecto, en Chile existen al menos 35 organizaciones formalmente constituidas (SIAE Consultores 2011: 12-29), las que actúan como agente promotor de políticas, denuncias y canalizador de respaldos internacionales (SIAE Consultores 2011). Las más reconocidas son: Chilesustentable, Terram, Oceana, Greenpeace Chile, Observatorio Ciudadano, Instituto de Ecología Política y OLCA. Nuestras cifras indican un involucramiento limitado en la generalidad de los conflictos, registrando una participación baja o nula en el $77 \%$ de los casos. Este patrón se explica por las carencias institucionales, financieras y de personal, que no permiten asumir la defensa de la totalidad de controversias en el país, por lo que privilegian centrar sus esfuerzos en casos de mayor impacto al medioambiente o bien que generan mayor atención en la opinión pública. Así se comprende su presencia en la oposición a Pascua Lama, HidroAysén, Celco Valdivia y Barrancones, entre otras. En contrapartida, su baja participación se registra en casi todos los rubros: hidroeléctrico (38\%), minero (42\%) y termoeléctrico (54\%). El mayor grado de activismo es contra la salmonicultura, a través de campañas y de material de difusión, que se insertan dentro de un contexto internacional de oposición al rubro.

En cuanto a su rol, las ONG tienen un impacto significativo en la condición de los conflictos, pues cuando demuestran activismo se vinculan al $67 \%$ de los consolidados, aunque su nivel de eficacia desciende en lo referido a la paralización de proyectos, pues solo un 50\% de estos casos ha contado con intervención permanente desde las ONG.

LA COBERTURA A LOS CONFLICTOS ES DE CARÁCTER INTERMEDIO EN LOS MEDIOS TRADICIONALES DE COMUNICACIÓN Y LIMITADA (PERO AL ALZA) EN LOS DIGITALES

En general, las controversias no son una materia de interés para los medios de comunicación, pues no existe un seguimiento permanente sobre el tema. Solo un $14 \%$ de los casos tiene un alto nivel de cobertura y 
un $47 \%$ un grado medio. Según la evidencia, no existe preferencia hacia un sector en específico, pues la cobertura se distribuye normalmente en todos los rubros. Sin embargo, uno de los aspectos que genera mayor atractivo es la judicialización de los conflictos, específicamente cuando la autoridad judicial rechazó proyectos a partir de recursos presentados por la comunidad (Parque Eólico Ancud, El Morro). En el caso opuesto, factores que no generan la atracción esperada — pese a su constatada importanciason la invocación al Convenio 169 de la OIT, los conflictos por el agua o las polémicas por la intervención en zona protegida. Lo mismo ocurre con la cantidad de años de los conflictos. Donde sí existe relación es entre la cobertura y el nivel de involucramiento de las ONG y el grado de articulación de la oposición, pues con un mayor grado de ambas existe un mayor despliegue de los medios en torno al conflicto. Principalmente, porque estos grupos cuentan con los conocimientos apropiados para formular campañas informativas que visibilicen el caso ante la opinión pública.

En cuanto a la utilización de las redes sociales, casi la mitad de los casos de la oposición no hace uso de estas herramientas digitales, desaprovechando las oportunidades que otorgan, como la autoproducción y difusión de información, sin límites y a bajo costo. Solo en un $21 \%$ se constató el uso de esta opción, aunque se debe considerar que existe poca utilización del medio debido a su carácter reciente en nuestro país. Por otra parte, no hay un rubro específico en que se destaque su uso como plataforma de oposición. Solo hay cinco casos con una alta utilización de este instrumento: Castilla, Pascua Lama, Barrancones, HidroAysén y Alto Maipo que se presentan como las más significativas de cada sector (Observatorio de Redes Sociales 2013). Y si bien cuatro de ellos se encuentran con algún tipo de traba institucional en su operación, no se puede demostrar que exista una asociación entre el uso de redes digitales y los impedimentos a los proyectos.

\section{EXISTE UN ALTO ÍNDICE DE DIFICULTADES INSTITUCIONALES: MÁS DE UN CUARTO DE LAS INICIATIVAS TIENE ALGÚN TIPO DE IMPEDIMENTO EN SU OPERACIÓN}

Uno de los mejores indicadores para evaluar el impacto de la oposición es comprobar si los proyectos cuentan con algún tipo de impedimento legal que altere o retrase su funcionamiento ${ }^{27}$. Según las cifras, el $28 \%$ enfrenta algún tipo de traba, siendo la institucionalidad ambiental la principal causa (50\%), el $36 \%$ por dictámenes de la justicia y el $14 \%$ por desistimiento de

27 Existen cinco opciones: suspendido, desistido, rechazado por la justicia, rechazado por la autoridad ambiental o en revisión en el Comité de Ministros. 
los propios titulares de los proyectos. Se pudo observar una relación entre la situación legal del proyecto y el ańo de origen de la controversia: existe una mayor tendencia de rechazo en el último tiempo, pues el $71 \%$ de los casos con dificultades se relacionan a proyectos originados en los últimos cinco años.

Por otra parte, existen tres variables que se destacan como transversalmente influyentes en la paralización de proyectos: la oposición política, la judicialización y la cobertura comunicacional. A partir del análisis de casos, se comprueba que cuando dichos factores se expresan en alta intensidad, los impedimentos tienden a tener mayor probabilidad de ocurrencia. Los actores políticos porque cuentan con poder para influir en los procesos decisionales de la aprobación ambiental; la judicialización porque posee la fuerza efectiva para revertir la luz verde de un proyecto, incluso contraviniendo lo resuelto por la autoridad administrativa. Finalmente, la cobertura comunicacional, porque tiene la capacidad de transmitir estas controversias a la esfera pública, estimulando su discusión en autoridades y ciudadanos, y contribuyendo a una mayor exigencia y fiscalización de las industrias según su impacto ambiental.

\section{Gráfico 6: Impedimentos legales según años de conflictos}
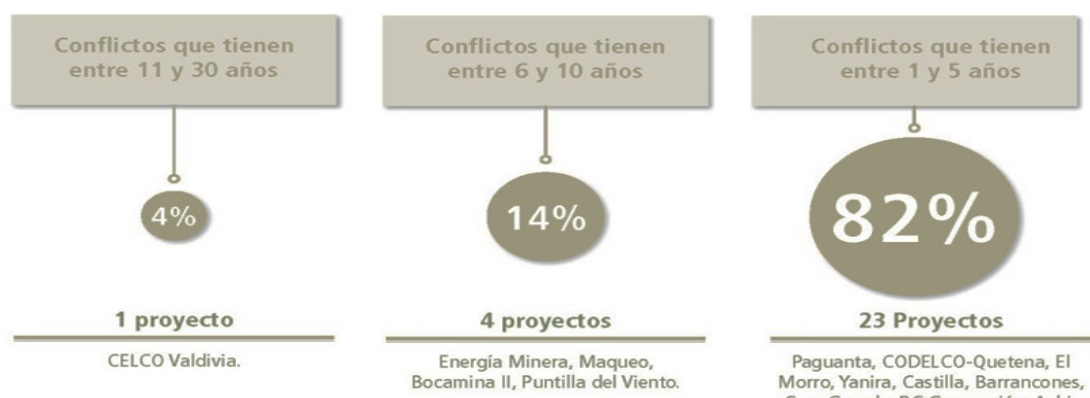

Paguanta, CODELCO-Quetena, EI Morro, Yanira, Castilla, Barrancones, bueno, Aguas Calientes, Río Cuervo, EI Panul, Embalse Nilahue, Biogesur. Parque Élico Ancud, Pacífico, Patache, Punta Alcalde, Tagua Tagua, Los Cóndores, Agrosuper Freirina, Colhue, HidroAysén.

Fuente: Elaboración propia. 
Este índice de conflictividad pretende distinguir y jerarquizar la intensidad de la oposición hacia los proyectos, a través de la parametrización de variables intervinientes que impactan negativamente a las empresas en las esferas de producción, relaciones y capital reputacional. Esta metodología, fundada en doce variables proxy, mide el grado de fuerza con que se ha manifestado cada conflicto a través de la asignación de valores a los indicadores correspondientes. La sumatoria de todos ellos genera un valor en una escala de 0 a 100 , existiendo una correlación positiva entre la puntuación y el nivel de intensidad. Con el objetivo de categorizar estos puntajes, se formularon cuatro niveles de medición, siendo los de intensidad baja aquellos casos con una puntuación de 0 a 25 puntos. Los de nivel medio se asignan a los que contabilizaron entre 26 y 50 puntos, mientras que los de condición alta para el rango 51 a 75 . Finalmente, los casos extremo a los que obtuvieron entre 76 y 100 puntos. 


\section{Tabla 2: Ponderación de intensidad de los conflictos}

\section{Perfil de oposición \\ (60 puntos)}

\section{Estrategias de la \\ oposición}

(15 puntos)

\section{Cobertura}

comunicacional

(25 puntos)
1. Nivel de organización $(0 / 20)$
a. Bajo: 5

b. Medio: 10

c. Alto: 15

d. Institucionalizado: 20

2. Cantidad de actores opositores $(0 / 12)$

a. Menos de 3 grupos: 4

b. Entre 3 y 5 grupos: 8

c. Más de 5 grupos: 12

3. Involucramiento ONG $(0 / 9)$
a. Nulo: 0
b. Bajo: 3
c. Medio: 6
d. Alto: 9

4. Apoyo internacional $(0 / 8)$
a. No: 0
b. Si: 8

5. Años de resistencia (0/6)

a. Menos de 2 años: 2

b. De 2 a 10 años: 4

c. Más de 11 años: 6
6. Acciones de violencia

$(0 / 4)$
a. No: 0

b. Si: 4

7. Judicialización nacional $(0 / 4)$
a. No: 0
b. Si: 4

8. Judicialización internacional $(0 / 8)$
a. No: 0
b. Si: 8

9. Resolución judicial en contra del proyecto $(0 / 3)$
a. No: 0
b. Si: 3

10. Tradicionales $(0 / 12)$

a. Baja: 4

b. Media: 8

c. Alta: 12

11. Redes Sociales (0/9)

b. Media: 6

c. Alta: 9

12. Internacionales $(0 / 4)$

a. No: 0

b. Si: 4

Calificación de intensidad

Baja: 0-25, Media: 26-50, Alta: 51-75, Extrema: 76-100. Fuente: Elaboración propia. 


\section{Tabla 3: Ranking histórico de intensidad de los conflictos}

(2000-2013)

\begin{tabular}{|c|c|c|c|c|c|c|c|}
\hline N. ${ }^{\circ}$ & Proyecto & Región & Industria & $\begin{array}{l}\text { Inversión, } \\
\text { en millones } \\
\text { de dólares }\end{array}$ & Conflicto & Situación & Puntaje \\
\hline 1 & Pascua Lama & III & Minería & 1.450 & Consolidado & Con trabas & 97 \\
\hline 2 & HidroAysén & XI & Hidroeléctrica & 3.200 & Consolidado & Con trabas & 89 \\
\hline 3 & Endesa Alto Bío Bío & VIII & Hidroeléctrica & 470 & Consolidado & Sin trabas & 87 \\
\hline 4 & Celco Valdivia & XIV & Forestal & 1.045 & Consolidado & Con trabas & 82 \\
\hline 5 & Los Pelambres & IV & Minería & 1.158 & Consolidado & Sin trabas & 79 \\
\hline 6 & Mainstream & $\mathrm{X}$ & Salmonicultura & 0,8 & Consolidado & Sin trabas & 78 \\
\hline 7 & Marine Harvest & $\mathrm{X}$ & Salmonicultura & 11 & Consolidado & Sin trabas & 78 \\
\hline 8 & Barrancones & IV & Termoeléctrica & 1.100 & Concluido & Con trabas & 76 \\
\hline 9 & Codelco Ventanas & V & Minería & 3 & Consolidado & Sin trabas & 75 \\
\hline 10 & Castilla & III & Termoeléctrica & 4.400 & Consolidado & Con trabas & 71 \\
\hline 11 & Alto Maipo & RM & Hidroeléctrica & 700 & Activo & Sin trabas & 65 \\
\hline 12 & Codelco El Salvador & III & Minería & S/I & Consolidado & Sin trabas & 65 \\
\hline 13 & Neltume & XIV & Hidroeléctrica & 820 & Activo & Sin trabas & 65 \\
\hline 14 & Bocamina II & VIII & Termoeléctrica & 184 & Activo & Con trabas & 60 \\
\hline 15 & Mina Invierno & XII & Minería & 180 & Activo & Sin trabas & 58 \\
\hline 16 & Eólico Ancud & $\mathrm{X}$ & Otros & 250 & Activo & Con trabas & 58 \\
\hline 17 & Cerro Casale & III & Minería & 5.200 & Activo & Sin trabas & 57 \\
\hline 18 & Pureo de Copec & $\mathrm{X}$ & Otros & 25 & Activo & Sin trabas & 57 \\
\hline 19 & Guacolda & III & Termoeléctrica & 230 & Consolidado & Sin trabas & 56 \\
\hline 20 & Pellets CMP & III & Otros & S/I & Consolidado & Sin trabas & 56 \\
\hline 21 & Biogesur & XIV & Otros & 0,1 & Concluido & Con trabas & 55 \\
\hline 22 & Celco Constitución & VII & Forestal & 10 & Consolidado & Sin trabas & 53 \\
\hline 23 & El Tatio & II & Otros & 20 & Incipiente & Con trabas & 53 \\
\hline 24 & Tagua Tagua & VI & Termoeléctrica & 95 & Activo & Con trabas & 52 \\
\hline 25 & AS-Freirina & III & Agroindustria & 500 & Activo & Con trabas & 51 \\
\hline 26 & Pacífico & I & Termoeléctrica & 750 & $\mathrm{Al}$ alza & Sin trabas & 51 \\
\hline 27 & Patache & I & Termoeléctrica & 150 & $\mathrm{Al}$ alza & Sin trabas & 51 \\
\hline 28 & Río Cuervo & XI & Hidroeléctrica & 733 & Activo & Con trabas & 51 \\
\hline 29 & El Panul & RM & Construcción & 80 & Activo & Con trabas & 50 \\
\hline 30 & Los Robles & VII & Termoeléctrica & 1.300 & Activo & Sin trabas & 50 \\
\hline 31 & Punta Alcalde & III & Termoeléctrica & 1.400 & $\mathrm{Al}$ alza & Con trabas & 50 \\
\hline 32 & Pullinque & XIV & Hidroeléctrica & 37 & Consolidado & Sin trabas & 49 \\
\hline 33 & Angostura & VIII & Hidroeléctrica & 500 & Activo & Sin trabas & 48 \\
\hline
\end{tabular}




\begin{tabular}{|c|c|c|c|c|c|c|c|}
\hline N. ${ }^{\circ}$ & Proyecto & Región & Industria & $\begin{array}{l}\text { Inversión, } \\
\text { en millones } \\
\text { de dólares }\end{array}$ & Conflicto & Situación & Puntaje \\
\hline 34 & Dunas Concón & $\mathrm{V}$ & Construcción & S/I & Activo & Con trabas & 48 \\
\hline 35 & Licancel & VII & Forestal & S/I & Declinación & Sin trabas & 48 \\
\hline 36 & El Morro & III & Minería & 2.514 & Activo & Con trabas & 47 \\
\hline 37 & Santa María & VIII & Termoeléctrica & 1.000 & Activo & Sin trabas & 47 \\
\hline 38 & Aeropuerto & IX & Construcción & 40 & Activo & Sin trabas & 46 \\
\hline 39 & Paipote & III & Minería & S/I & Consolidado & Sin trabas & 46 \\
\hline 40 & Puntilla de Viento & $\mathrm{V}$ & Construcción & 115 & Declinación & Con trabas & 46 \\
\hline 41 & CMPC Celulosa & IX & Forestal & S/I & Declinación & Sin trabas & 45 \\
\hline 42 & Forestal Arauco & IX & Forestal & S/I & Activo & Sin trabas & 45 \\
\hline 43 & Campiche & $\mathrm{V}$ & Termoeléctrica & 500 & Activo & Sin trabas & 44 \\
\hline 44 & Codelco El Teniente & $\mathrm{RM}$ & Minería & S/I & Declinación & Sin trabas & 44 \\
\hline 45 & Codelco/Soquimich & II & Minería & 7 & Consolidado & Sin trabas & 44 \\
\hline 46 & Los Pumas & $\mathrm{XV}$ & Minería & 100 & $\mathrm{Al}$ alza & Sin trabas & 44 \\
\hline 47 & Pirquenes & VIII & Termoeléctrica & 82 & Activo & Con trabas & 44 \\
\hline 48 & Cruz Grande & IV & Termoeléctrica & 460 & Concluido & Con trabas & 43 \\
\hline 49 & Achibueno & VII & Hidroeléctrica & 285 & Activo & Sin trabas & 42 \\
\hline 50 & E-CL & II & Termoeléctrica & S/I & Consolidado & Sin trabas & 41 \\
\hline 51 & Maqueo & XIV & Hidroeléctrica & 1.000 & Activo & Con trabas & 41 \\
\hline 52 & Norgener & II & Termoeléctrica & 190 & Consolidado & Sin trabas & 41 \\
\hline 53 & Parinacota & $\mathrm{XV}$ & Termoeléctrica & 40 & Activo & Sin trabas & 41 \\
\hline 54 & Picoiquén & IX & Hidroeléctrica & 48 & Declinación & Sin trabas & 41 \\
\hline 55 & Trupanco & VIII & Hidroeléctrica & 42 & Activo & Sin trabas & 41 \\
\hline 56 & Collahuasi-Lequena & II & Minería & 173 & Declinación & Con trabas & 40 \\
\hline 57 & Relleno Chiloé & $\mathrm{X}$ & Otros & 5,5 & Activo & Sin trabas & 40 \\
\hline 58 & Aguas Batuco & $\mathrm{RM}$ & Otros & 9 & $\mathrm{Al}$ alza & Sin trabas & 39 \\
\hline 59 & Catanave & $X V$ & Minería & 1 & Activo & Sin trabas & 39 \\
\hline 60 & Los Colorados & $\mathrm{RM}$ & Otros & 40 & Activo & Sin trabas & 38 \\
\hline 61 & Angamos & II & Termoeléctrica & 1000 & Activo & Sin trabas & 37 \\
\hline 62 & El Manzano & IV & Minería & 7 & Activo & Sin trabas & 37 \\
\hline 63 & Transmisión Freire & IX & Otros & 17 & Activo & Sin trabas & 37 \\
\hline 64 & Tres Valles & IV & Minería & 102 & Activo & Sin trabas & 37 \\
\hline 65 & Colhue & VI & Otros & 1 & Declinación & Con trabas & 36 \\
\hline 66 & Choquelimpie & $\mathrm{XV}$ & Minería & 0,5 & Incipiente & Sin trabas & 35 \\
\hline 67 & Los Condores & VII & Hidroeléctrica & 180 & Activo & Con trabas & 35 \\
\hline 68 & Paguanta & I & Minería & 5 & Activo & Con trabas & 35 \\
\hline
\end{tabular}




\begin{tabular}{|c|c|c|c|c|c|c|c|}
\hline N. ${ }^{\circ}$ & Proyecto & Región & Industria & $\begin{array}{l}\text { Inversión, } \\
\text { en millones } \\
\text { de dólares }\end{array}$ & Conflicto & Situación & Puntaje \\
\hline 69 & Codelco Andina & RM & Minería & $S / I$ & $\mathrm{Al}$ alza & Sin trabas & 34 \\
\hline 70 & San Pedro & XIV & Hidroeléctrica & 202 & Activo & Sin trabas & 34 \\
\hline 71 & AS-Melipilla & $\mathrm{RM}$ & Agroindustria & 7 & Activo & Sin trabas & 33 \\
\hline 72 & Celco Teno & VII & Forestal & 110 & Activo & Sin trabas & 33 \\
\hline 73 & Central Nuble & VIII & Hidroeléctrica & 140 & Activo & Sin trabas & 33 \\
\hline 74 & AS-Cardenal Caro & VI & Agroindustria & $S / I$ & Activo & Sin trabas & 33 \\
\hline 75 & Quebrada Honda & VI & Agroindustria & 18 & Activo & Sin trabas & 33 \\
\hline 76 & Milena & IV & Minería & $S / I$ & Activo & Sin trabas & 32 \\
\hline 77 & Carmen & IV & Minería & 350 & Declinación & Sin trabas & 31 \\
\hline 78 & Celco Nueva Aldea & VIII & Forestal & 150 & Declinación & Sin trabas & 31 \\
\hline 79 & Nehuenco & V & Termoeléctrica & 484 & Activo & Sin trabas & 31 \\
\hline 80 & Osorno y Rucatayo & XIV & Hidroeléctrica & 120 & Activo & Sin trabas & 31 \\
\hline 81 & Aguas Calientes & VIII & Hidroeléctrica & 80 & Declinación & Con trabas & 30 \\
\hline 82 & Energía Minera & V & Termoeléctrica & 1.700 & Activo & Con trabas & 30 \\
\hline 83 & Mediterráneo & $\mathrm{X}$ & Hidroeléctrica & 400 & Activo & Sin trabas & 30 \\
\hline 84 & Olga & $\mathrm{XV}$ & Minería & S/I & $\mathrm{Al}$ alza & Sin trabas & 29 \\
\hline 85 & Codelco Quetena & II & Minería & 244 & Incipiente & Sin trabas & 28 \\
\hline 86 & Energía del Sur & $\mathrm{X}$ & Hidroeléctrica & $S / I$ & Incipiente & Sin trabas & 28 \\
\hline 87 & RC Generación & V & Termoeléctrica & 1.081 & Declinación & Con trabas & 28 \\
\hline 88 & Los Bronces & RM & Minería & 2.000 & $\mathrm{Al}$ alza & Sin trabas & 27 \\
\hline 89 & Colmillos & IV & Minería & 1 & Incipiente & Sin trabas & 26 \\
\hline 90 & Embalse Nilahue & VI & Construcción & 6 & Declinación & Con trabas & 25 \\
\hline 91 & ERA Concón & V & Termoeléctrica & 390 & Activo & Sin trabas & 25 \\
\hline 92 & La Higuera & VI & Hidroeléctrica & 500 & Activo & Sin trabas & 25 \\
\hline 93 & Cinabrio & IV & Minería & 5 & Activo & Sin trabas & 24 \\
\hline 94 & Pangui & IX & Hidroeléctrica & 21 & Activo & Sin trabas & 23 \\
\hline 95 & Linderos & IV & Minería & 0,5 & Activo & Sin trabas & 21 \\
\hline 96 & San Isidro & V & Termoeléctrica & 200 & Activo & Sin trabas & 20 \\
\hline 97 & Celco Horcones & VIII & Forestal & S/I & Incipiente & Sin trabas & 16 \\
\hline 98 & Central El Paso & VI & Hidroeléctrica & 52 & Activo & Sin trabas & 16 \\
\hline 99 & Dayton & IV & Minería & 32 & Activo & Sin trabas & 16 \\
\hline 100 & El Relincho & III & Minería & 11 & Activo & Sin trabas & 16 \\
\hline
\end{tabular}

Fuente: Elaboración propia. 
Los datos estadísticos muestran que el promedio de puntaje es de 43,9 puntos, ubicándose en un nivel de tipo medio. La desviación estándar es de 17 puntos. Por su parte, la moda es de 40, también encontrándose en el nivel medio de intensidad.

\section{MODELOS DE CONFLICTO SEGÚN INTENSIDAD}

En este apartado se expone una caracterización -a través de rasgos y patrones comunes-, de los tipos de conflicto socioambiental según el grado de fuerza con que se manifiesta la oposición a los proyectos.

\section{INTENSIDAD EXTREMA}

En Chile, los conflictos socioambientales de este tipo son ocho y se caracterizan por no tener un patrón de concentración geográfica. En el caso de las industrias involucradas, se identifica al menos un conflicto representativo en cada una de ellas, exceptuando al sector Construcción y otros. En la configuración de los grupos opositores, son al menos cinco tipos de organizaciones las que se resisten a los proyectos, destacándose la perfecta conjunción de los sectores locales, ambientalistas y políticos. El mecanismo de interacción sería el siguiente: los primeros son los encargados del activismo y la movilización; los segundos otorgan capacitación y asesoría jurídica a dichas comunidades y los políticos funcionan como canales de comunicación ante las autoridades, a quienes hacen presente los requerimientos de los ciudadanos. De este modo, la combinación simultánea de estos tres grupos supone una condición necesaria para que los conflictos alcancen una intensidad extrema.

Un fenómeno similar se vincula con el nivel de articulación de los grupos, por cuanto todos estos conflictos evidencian una alta profesionalización del descontento. En el plano estratégico, se registra en la totalidad de los casos la utilización del recurso judicial, aunque con efectos limitados. Si bien este nivel de institucionalización de la resistencia asegura una mayor exposición comunicacional del conflicto, no supone una cancelación o paralización efectiva del proyecto. Otra particularidad es que las ONG poseen una alta presencia, concentrando sus esfuerzos y recursos en el $88 \%$ de los casos. Esta condición de involucramiento no se replica en los otros niveles de intensidad del ranking, demostrándose la preferencia que tienen estas organizaciones por este tipo de casos. Asimismo, el apoyo internacional es altamente probable, pues se registra en el total de las controversias.

En el plano comunicacional, los medios focalizan sus recursos a través de una amplia cobertura en plataformas tradicionales y digitales, contribuyendo a su exposición y posicionamiento en la opinión pública. En ocasiones aparecen en la prensa internacional, aunque con impacto y 
difusión limitada.

Finalmente, la mayoría de estos conflictos se encuentran consolidados (88\%), lo que revela que la permanencia en el tiempo configura situaciones de mayor importancia, impacto y visibilidad en contra de los proyectos.

\section{INTENSIDAD ALTA}

Se identificaron veinte casos de este nivel, los que no poseen un patrón de distribución respecto al tipo de zona (urbano/rural) y región de emplazamiento. No obstante, se destaca dentro de la muestra la región de Atacama que concentra un $30 \%$, lo que se relaciona con la presencia de una de las cinco zonas de sacrificio ${ }^{28}$ en nuestro país: la provincia de Huasco. En cuanto a las industrias, se destacan las termoeléctricas con un $30 \%$ de las controversias.

En lo relativo al modelo de oposición, son al menos tres los grupos de resistencia, siendo los más frecuentes los de tipo político y local. Los cinco tipos restantes son un complemento para la organización, destacándose la importancia de la oposición ciudadana y ambientalista en un gran número de conflictos, lo que confirma la focalización de recursos de las ONG.

En el $65 \%$ de los casos se observa un nivel de organización medio, con resistencia profesionalizada, capacidad de convocatoria y -en menor medida- con acceso a recursos para sostener la movilización.

En esta situación, el porcentaje de proyectos con trabas es mayor que en los conflictos con intensidad extrema. Un $40 \%$ de los casos poseen problemas de este orden, lo que refuerza la idea de que la paralización de un proyecto no depende exclusivamente del nivel de articulación de la oposición ni de la judicialización de los conflictos (85\%).

Por último, la cobertura de los medios tradicionales se presenta en un nivel medio y alto, reforzando la hipótesis de la focalización de los recursos en el despliegue de información de los conflictos más polémicos. Asimismo, en un $80 \%$ existe el uso de redes sociales como complemento a la resistencia.

28 Término acuñado por la ONG ambientalista Oceana para referirse a aquellos lugares que concentran una gran cantidad de industrias, encontrándose saturadas de contaminación. Dichas zonas son: Ventanas, Tocopilla, Mejillones, Huasco y Coronel. 


\section{INTENSIDAD MEDIA}

Esta es la categoría que distingue a la mayoría de los conflictos, al concentrar sesenta y un casos del total. Las regiones más relevantes son Bío Bío y Metropolitana (7), mientras que los otros casos se distribuyen sin un patrón geográfico en particular. En cuanto a la industria, el $72 \%$ se concentra en los rubros de la minería (18), hidroeléctricas (13) y termoeléctricas (13), quedando en evidencia la alta conflictividad en rubros estratégicos del país. Por último, se destaca que en su mayoría los conflictos se encuentran en un estado activo, constituyendo un fenómeno reciente, pues el 53\% corresponde a situaciones originadas hace menos de cinco años.

El modelo de oposición no se encuentra tan definido como en las categorizaciones anteriores. La cantidad de opositores se concentra entre tres y cuatro grupos, con un grado de organización medio (56\%). Los agentes políticos y locales siguen siendo los mayoritarios con un 79\% y $93 \%$ respectivamente, seguidos en un porcentaje relevante por la participación ciudadana (61\%). Este nivel medio de intensidad demuestra de mejor manera la realidad general de los grupos ambientalistas en Chile, un $89 \%$ de casos bajos y nulos en el grado de involucramiento de ONG.

Se destaca el recurso judicial como estrategia para estos grupos opositores, pues se registra en un $72 \%$ de los casos. Lo llamativo es que nueve casos han sido rechazados por la autoridad ambiental o de justicia, llegando a un $25 \%$ de proyectos con trabas en su operación. Lo anterior demuestra que la condición alta o extrema no necesariamente asegura mayores opciones de la paralización de un proyecto, pues su ocurrencia es transversal en términos de intensidad. Respecto a los elementos catalizadores de polémicas, se registra un aumento de los conflictos motivados por el agua (61\%).

La cobertura de medios en general cuenta con un nivel medio (53\%) y bajo (44\%). Solo dos casos tienen amplia cobertura: Colhue y Campiche. Este hecho se asocia a las acciones de los opositores, como tomas de caminos con alto impacto e irregularidades en el ámbito político. Por su parte, las redes sociales no son explotadas por los grupos opositores, ya que no difunden gran cantidad de información, teniendo peso relativo en la difusión e intensidad del conflicto.

\section{INTENSIDAD BAJA}

En esta categoría se registran once casos, ubicándose principalmente en zonas de carácter rural (55\%), aunque sin un patrón definido en cuanto a la región, ni al tipo de industria. En ese sentido, la mayor ocurrencia de controversias en espacios rurales explica que el $73 \%$ de los conflictos 
sea producto de disputas por el agua, en tanto dicho recurso supone un elemento central para los intereses de las comunidades locales.

La oposición en este tipo de casos se caracteriza por su baja densidad e intensidad. El 90\% de los eventos cuenta con dos grupos de oposición, siendo la presencia de comunidades locales y autoridades políticas la frecuencia más recurrente. Este modelo cooperativo se comprende por el beneficio mutuo que supone para ambos agentes: las comunidades obtienen mayor posicionamiento de su caso a través del involucramiento de actores políticos, mientras que estos últimos utilizan la instancia para generar sintonía y ampliar sus redes de apoyo en las bases electorales.

Respecto a las acciones emprendidas, no se identifica una estrategia integral y de largo plazo en la oposición. La judicialización no se explota como alternativa (27\%), probablemente por la escasa preparación de los grupos de oposición y el desconocimiento que tienen sobre la eventual efectividad de este tipo de recursos. Asimismo, el uso de la violencia es limitado (18\%) producto de la ausencia de eventos críticos que estimulen la reacción de las comunidades.

Finalmente, en el plano comunicacional, estos conflictos suponen el nivel más bajo de cobertura, tanto en medios tradicionales como plataformas digitales. Los grupos de resistencia no formulan un plan de acción comunicacional que difunda en las audiencias su lucha particular. Por el contrario, esperan la cobertura desde los medios tradicionales, desconociendo el potencial informativo y democratizador de las nuevas tecnologías.

\section{CONCLUSIONES}

En este trabajo formulamos una visión general sobre el problema de los conflictos socioambientales, que es representativo de los signos de cambio social en el Chile de hoy. Dimos cuenta de la extensión del fenómeno a través de evidencia empírica y análisis inferenciales que intentaron explicar, distinguir y ponderar la dinámica propia de estas controversias. A pesar de sus limitaciones y carencias, el instrumento metodológico propuesto supone un aporte para futuras investigaciones, constituyéndose como uno de los primeros pasos para el mejoramiento en la comprensión de los conflictos socioambientales como fenómeno integral.

Quedó en evidencia que estas controversias no son un fenómeno aislado ni focalizado. Por el contrario, los resultados apuntaron a demostrar que poseen una tendencia al alza, especialmente si se considera el aumento del número de casos en los últimos cinco años. Instancias como la 
judicialización, la invocación al Convenio 169 de la OIT, al auge de los conflictos por el agua y el aumento en la fiscalización desde la autoridad, permiten vislumbrar un escenario de mayor complejidad para los proyectos inversionistas, aunque en una magnitud esperable para países que incorporan valores y lógicas asociadas a una sociedad post materialista (Beck, Giddens y Lash 2008).

Asimismo, el presente estudio permitió refutar ideas y percepciones que hasta ahora parecían ciertas. Por ejemplo, la creencia de un despliegue significativo de las ONG ambientalistas en los territorios afectados, cuando en realidad poseen un escaso nivel de involucramiento en la totalidad de los conflictos (por un tema de recursos, más bien focalizan sus esfuerzos en las controversias de mayor impacto y visibilidad). Asimismo, se develó como mito la excesiva injerencia de ONG extranjeras en los conflictos local, pues lo cierto es que el apoyo en recursos y financiamiento es limitado. O bien la poca relevancia de las acciones de violencia como estrategia de oposición, entre otros elementos. Estas realidades parecen indicar que la configuración de las controversias socioambientales son complejas y que los patrones que las caracterizan son principalmente de orden local.

Por último, a través del nivel de intensidad de la oposición, la investigación contribuyó a sustentar metodológicamente la relevancia de ciertos conflictos, jerarquizando los casos y entregando valor a la información disponible, tanto para el gobierno, los agentes inversionistas y los grupos interesados de la sociedad civil. 


\section{REFERENCIAS}

Auditoría a la Democracia. (2012). Estudio Nacional de Opinión Pública. Santiago: Auditoría a la Democracia.

Beck, U., Giddens, A. y Lash, S. (2008). Modernización Reflexiva: Politica, Tradición y Estética en el Orden Social Moderno. Madrid: Alianza Editorial.

Cámara de Diputados. (2011). Informe de la Comisión Investigadora Sobre la Situación en que se Encuentran los Depósitos de Relaves Mineros Existentes en el Pais. Disponible en http://www.camara.cl

Chilesustentable. (2010). Conflictos Sociales por el Agua en Chile: Entre los Derechos Humanos y las Reglas del Mercado. Santiago: Embajada de $\mathrm{Hz}$ olanda, Chilesustentable:

Coser, L. (1965). Las Funciones del Conflicto Social. México: Fondo de Cultura Económica.

Dalton, R., Van Sickle, A. y Weldon, S. (2010). The Individual-Institutional Nexus of Protest Behaviour. British Journal of Political Science, 40 (1), 51-73.

Della Porta, D. y Diani, M. (1999). Social Movements: An Introduction. Oxford: Blackwell.

Freund, J. (1995). Sociología del Conflicto. Madrid: Editorial del Ministerio de Defensa.

Fundación Terram. (2001). Salmonicultura en Chile: Desarrollo, Proyecciones e Impacto. Santiago: Fundación Terram.

González Calleja, E. (2013). El Laboratorio del Miedo. Una Historia General del Terrorismo Barcelona: Crítica.

Instituto Nacional de Derechos Humanos. (2012). Mapa de Conflictos Socioambientales en Chile. Santiago: Instituto Nacional de Derechos Humanos.

Larraín, L. (2011). El Regreso del Modelo. Santiago: Libertad y Desarrollo.

Latinobarómetro. (2011). Informe 2011. Santiago: Latinobarómetro.

Lorenzo, P. (2001). Fundamentos Teóricos del Conflicto Social. Madrid: Siglo XXI Editores. 
Mayol, A. y Azócar, C. (2011). Politización de malestar, Movilización Social y Transformación Ideológica: El Caso Chile 2011. Revista Polis, 30, 2-19.

- El Derrumbe del Modelo. La Crisis de la Economía de Mercado en el Chile Contemporáneo. Santiago: LOM Ediciones.

Montt, S. y Matta, M. (2011). Una Visión Panorámica al Convenio OIT 169 y su Implementación en Chile. Estudios Públicos, 121, 133-212.

Moulian, T. (1997). Chile Actual. Anatomía de un Mito. Santiago: LOM Ediciones.

Navarrete, J. (2011). No Va Más. La Tercera, 12 de junio.

Observatorio de Redes Sociales. (2013). Activismo Medioambiental 2.0. Santiago: Obervatorio de Redes Sociales.

Oppliger, M. y Guzmán, E. (2012). El Malestar en Chile ¿Teoría o Diagnóstico? Santiago: RIL Editores.

Oro, L. (2013). El Concepto de Realismo Político. Santiago: RIL Editores, CAIP.

Qué Pasa. (2012). Inversión en Jaque”, Qué Pasa, 15 de noviembre.

Reyes, F., Frontaura, C., Leturia, F., Castillo, C., Trigo, P. y Vallejo. (20119. Propuesta de Mecanismos de Resolución Colaborativa de Conflictos Socioambientales. En Pontifica Universidad Católica de Chile, Propuestas para Chile: Concurso Políticas Públicas 2011. Santiago: Centro de Políticas Públicas UC.

Rosen, J. (2001). What Are Journalists For? New Haven: Yale University Press.

Salazar, G. (2012). En el Nombre del Poder Popular Constituyente (Chile, Siglo XXI). Santiago: LOM Ediciones.

Segovia, C. y Gamboa, R. (2012). Chile: El Año en que Salimos a la Calle. Revista de Ciencia Politica, 32 (1), 65-85.

SIAE Consultores (2011). Organizaciones Ambientalistas: Alcances, Perspectivas y Relaciones en los Conflictos Medioambientales de Chile. Santiago: SIAE Consultores.

Skoknic, F. (2013). El Nuevo Periodismo de Investigación: Digital y Sin Fines de Lucro. En Arriagada, A. y Navia, P. (Eds.), Intermedios. Medios 
de Comunicación y Democracia en Chile. Santiago: Ediciones UDP.

Sociedad de Fomento Fabril (SOFOFA). (2011). Catastro de Proyectos de Inversión. Santiago: SOFOFA.

Tarrow, S. (2009). El Poder en Movimiento. Los Movimientos Sociales, la Acción Colectiva y la Política. Madrid: Alianza Editorial.

The World Commission on Dams. (2000). Represas y Desarrollo: Un Nuevo Marco para la Toma de Decisiones. Santiago: The World Commission on Dams

Tilly, C. (2010). Los Movimientos sociales, 1768-2008. Desde sus Orígenes a Facebook. Barcelona: Crítica.

Universidad Diego Portales (UDP). 2011. Encuesta Nacional UDP 2011. Santiago: Universidad Diego Portales.

UDP-Feedback. (2012). Encuesta de Opinión Pública: Participación de Jóvenes 2012. Santiago: Universidad Diego Portales, Feedback.

Van Dyke, N. (2003) Protest Cycles and Party Politics: The Effects of Elite Allies and Antagonists on Student Protest in the United States, 1930-1990. En Goldstone, J. (Ed.), States, Parties and Social Movements. New York: Cambridge University Press.

Recibido: 02-11-2015

Aceptación de la versión final: 18-12-2015 